\title{
Artifacts and Mind-Dependence
}

\author{
Tim Juvshik
}

Penultimate draft - please cite the published version (Synthese 2021 https://doi.org/10.1007/s11229-021$\underline{03204-6)}$

Abstract: I defend the intention-dependence of artifacts (IDA), which says that something is an artifact of kind $K$ only if it is the successful product of an intention to make an artifact of kind $K$. I consider objections from two directions. First, that artifacts are often mind- and intention-dependent, but that this isn't necessary, as shown by swamp cases. I offer various error theories for why someone would have artifact intuitions in such cases. Second, that while artifacts are necessarily mind-dependent, they aren't necessarily intention-dependent. I consider and reject three kinds of cases which purport to show this: accidental creation, automated production, and mass production. I argue that intentions are present in all of these cases, but not where we would normally expect.

\section{Introduction}

We're all familiar with many different kinds of artifacts, from the mundane - pencils, shoes, cellphones, cars, chairs, books - to the more esoteric - submarines, spandrels, nuclear reactors, GPS satellites, lithium ion batteries. Philosophical interest in artifacts has recently exploded, with many proposals put forth for understanding whether artifacts have essential natures and what such a nature is like. A common proposal for artifact essences is that they are things intentionally made to serve some purpose or fulfill some goal or function. This common view involves two components: that artifacts have functions and that they are the intentional products of human creative acts. Both components have substantial pre-theoretic plausibility. If asked what chairs or hammers or teacups are, the lay person will likely say that they are things created to perform the function characteristic of their kind. Intuitively, a chair, say, is a piece of furniture that someone intentionally made to be used for sitting. Thus, artifacts appear to be functional objects which are mind-dependent and more specifically intention-dependent.

Despite their pre-theoretic plausibility, both aspects of artifacts have received substantial theoretical defenses. The vast majority of the literature has focused on artifact functions - whether artifacts are functional kinds, what the appropriate analysis of artifact functions is, and whether functions can serve as essences. ${ }^{1}$ Whether this monolithic focus on function is justified remains to be seen. ${ }^{2}$ Regardless, I won't add to those debates here but instead want to focus on the intention-

\footnotetext{
${ }^{1}$ For representative discussion of artifact functions see Kornblith (1980), Dipert (1993), Houkes and Vermaas (2004), Baker (2007), Elder (2007), Soavi (2009), Hughes (2009), Franssen and Kroes (2014), and Evnine (2016).

${ }^{2}$ For discussion on the state of the artifact function literature, see Preston (2009), Koslicki (2018, ch. 8), Olivero (2019), and my (Juvshik 2021).
} 
dependence of artifacts, which is equally widely accepted but slightly less discussed in the literature. ${ }^{3}$ Indeed, the intention-dependence of artifacts seems so plausible that it's often taken as a starting point in philosophical inquiries into the nature of artifacts and artifact kinds. Most of these proposals assume that artifacts are the products of an intention to make such a thing. The notion of intentiondependence will be clarified going forward, but for now consider the following case: to make a chair, say, a carpenter at least requires an intention to make a chair. A carpenter can't just intend to make anything, nor can she merely have an intention to make an artifact. Rather, artifacts are products of an intention to make that kind of thing. Thus, whatever else the essential nature of artifacts involves, artifacts are at least essentially intention-dependent.

There are two kinds of challenges to the intention-dependence of artifacts, which we can call metaphysical and extensional challenges, respectively. Much of the literature has focused on metaphysical challenges which most often stem from realist worries. Realists argue that to be real, to be really real, in some metaphysically respectable or heavyweight sense requires mind-independence. ${ }^{4}$ Entities that are mind-dependent aren't real kinds - they are merely nominal or conventional kinds which are projected onto the world and whose nature is in some sense 'up to us' (e.g. Wiggins 2001, Zimmerman 2002, Lowe 2014). Realism requires a mind-independent essence. The ontological status of artifacts (as well as institutional kinds like money or marriage) is thereby impugned by their apparent intention-dependence. Such metaphysical challenges to the reality of artifacts have spawned various attempts to offer mind-independent artifact essences (e.g. Elder 2007), ${ }^{5}$ but their underlying assumptions have also been challenged. For example, Baker (2007) argues that in a broadly naturalist metaphysics, minds are as equally real as anything else so anything that results from or depends on the mind has as good a claim to real ontological status. In a slightly different vein, Thomasson (2007) has argued that the realist objections all conflate being a real kind with being a natural kind and she argues that we shouldn't expect the conditions for being a natural kind to be suited for or applicable to, artifacts. I take the arguments of Baker and Thomasson to determinately show that the realist challenges to the existence of artifacts are wrongheaded. Lots of things worth investigating depend on

\footnotetext{
${ }^{3}$ For the intention-dependence of artifacts, see Eaton (1969), Davies (1991), Hilpinen (1992), Dipert (1993), Bloom (1996), Thomasson (2003, 2007, 2009, 2014), Levinson (2007), Baker (2007), Grandy (2007), Mag Uidhir (2013), Franssen and Kroes (2014), and Evnine (2016). See also Houkes and Vermaas (2014) for a discussion of artifact mind-dependence from a classificatory point of view.

4 Or foot stompingly real, to use Arthur Fine's phrase.

5 See also Soavi (2009) and Franssen and Kroes (2014) for realist accounts of artifact essences which don't focus on mindindependence. Elder (2014) also changes his view slightly to allow for the mind-dependence of artifacts by construing realism as an epistemic thesis.
} 
minds and mental states - they're the subject of the social sciences and humanities, after all - so minddependence shouldn't undermine the metaphysical credibility of a class of entities.

Instead, I want to focus on extensional challenges to the intention-dependence of artifacts. Extensional challenges aren't generally motivated by realist worries, although sometimes they may come from realist quarters. Rather, extensional challenges claim that, while there is nothing metaphysically problematic with being mind- or intention-dependent, there are actual or possible cases which show that the mind- or intention-dependence of artifacts is merely apparent or contingent. Such challenges can come from two different directions. Despite the above natural (and seemingly pretheoretic) condition on artifactuality, one may think that while most artifacts happen to be minddependent and even intention-dependent, this is only a common, but not necessary, feature of artifacts. This mind-independence view is common in debates about mereology because it's the result of far-flung modal reasoning: we can imagine a possible world that is empty except for a single object that is intrinsically identical to my 2006 Honda Civic or alternatively, one may appeal to so-called swamp cases, where it's possible, however unlikely, that swamp gases coalesce into an object that is intrinsically identical to my 2006 Honda Civic. Some philosophers, especially in debates about composition and constitution, have the intuition that in both cases these are genuine artifacts,

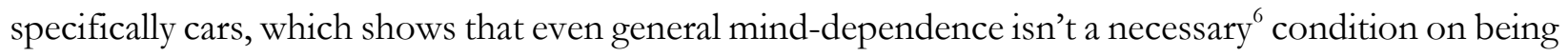
an artifact. $^{7}$

By contrast, one may argue that while artifacts are indeed mind-dependent, they aren't necessarily intention-dependent. Such a view may arise from very different quarters, namely by attending to the empirical details of our practices of making, using, and regarding artifacts. This kind of view can be motivated by cases of what seem like accidental creation, e.g. I don't intend to make a loaf of bread but through sheer clumsiness I do, cases of automated production where the artifact is made by machines or computer programs, and cases of mass production where the artifact is produced by a variety of agents. In all of these cases one may have the intuition that a genuine artifact has been created, but that the relevant intention to make such a thing is lacking. ${ }^{8}$

\footnotetext{
6 While Fine (1994) has distinguished between essentialist and necessity claims, for my purposes I treat them interchangeably since nothing hinges on this.

${ }^{7}$ For example, Merricks (2000), Wiggins (2001), and Koslicki (2008), while Elder (2007, 2014) and Khalidi (2016) raise such cases in non-mereological contexts. See Thomson (1998) for the standard presentation of such mereological problems that involves intention-dependence.

${ }^{8}$ Cases of accidental making are discussed by Lopes (2007) and Xhignesse (2020), while cases of automated and mass production are discussed by Hilpinen (1992, 60n7), Dipert (1993, 126-129), Kornblith (2007, 145), Preston (2013, 24-26), Evnine (2016, 97ff, 2019), and Koslicki (2018, 234-235).
} 
We thus have two possible extensional challenges to the claim that artifacts are necessarily intention-dependent:

(1) Artifacts aren't necessarily mind-dependent, but most of the artifacts around us happen to be.

(2) Artifacts are necessarily mind-dependent, but don't need to be intention-dependent.

The aim of this paper is to defend the intention-dependence of artifacts, or (IDA) for short, against (1) and (2), thereby securing a widespread but all too often unsupported condition on being an artifact.

The paper is structured as follows. In section 2 I motivate (IDA) as a condition on artifacts and expand a bit on what this condition entails. In section 3, I consider two kinds of cases in support of (1), modal cases and swamp cases. I argue that our intuitions in these cases are unreliable given how much of a departure they are from ordinary artifacts and thus what we say about such putative counterexamples are best left as spoils to the victor. Despite taking this approach, I also offer three potential error theories for explaining why someone might have the intuition despite its content being false. In section 4, I argue against three kinds of cases that appear to support (2), accidental creation, automated production, and mass production. I show how they all involve an intention to create an artifact, just not where we might initially expect it to be, while also considering various objections along the way, before briefly concluding in section 5. My defense of (IDA) won't sway any realists since their underlying metaphysical concerns about mind-dependence aren't addressed in this paper. Rather, for those who are willing to accept the mind- and intention-dependence of artifacts, I show how we can defend (IDA) as a condition on artifactuality from a number of putative counterexamples.

Before continuing, I want to note two assumptions I will make throughout this paper. First, is the plausible and widespread view that to be an artifact entails being a member of a particular artifact kind (or maybe more than one); there are no free-floating artifacts, so to speak. Second, I will assume that artifacts can be created by appropriation: I can move a piece of driftwood from the beach to my kitchen and thereby genuinely make a wine rack, say, and thus an artifact, without otherwise physically modifying it. I say more about appropriation in the next section. While artifact creation by appropriation is less widespread, it still has many adherents and as will become clear later, it yields powerful explanatory upshots. ${ }^{9}$

\section{The Intention-Dependence of Artifacts}

\footnotetext{
9 Those who endorse creation by appropriation include Hilpinen (1992, 64-65), Thomasson (2014, 53-54, n9), Baker (2007, 53n8), Evnine (2013), Koslicki (2018, 231n14), Preston (2013, 96-103), Scheele (2006), and Mag Uidhir (2013, 99-100, n7). See also Reydon (2014, 138-139).
} 
The intention-dependence of artifacts (IDA) is a plausible essential component of artifactuality which can be motivated by looking at our practices of making, using, and classifying artifacts. If artifacts are intention-dependent, then they are mind-dependent, since intention-dependence just is a kind of mind-dependence. Artifacts come into existence by the intentional acts of their creators. Desk chairs, computers and handsaws are all products of intentional action - someone intentionally did something to bring them into existence. Absent humans, or other entities with intentionality, it doesn't seem like there would be any reinforced concrete supertall skyscrapers or Toshiba copy machines or hybrid electric-gasoline motors. The existence of these entities clearly depends on the intentional actions of their creators, designers, and perhaps in some cases even users. Of course, not everything that results from intentional activity is an artifact. To borrow Stephen Davies' (1991, 131) example, if I intentionally cut off your arm, I've artifactualized neither you nor your arm. ${ }^{10}$ Thus, (IDA) is a plausible necessary, but not sufficient, condition on being an artifact. ${ }^{11}$

But what exactly do we mean when we say artifacts like chairs are intention-dependent? It can't merely be that they are causally dependent on some intention or other somewhere in the chain of causes that led to their existence. For example, a carpenter's great-grandparents intentionally had a child, and the carpenter's chair causally depends on their intention to have a child, and thus the chair is intention-dependent. This would be a trivial condition that wouldn't tie intention-dependence to artifactuality in any obviously relevant or essential way. Rather, to be an artifact, say a chair, it must be the product of an intention to make a chair. Chairs, curling irons, and violins are all things that satisfy such a condition. When an artisan makes a violin, it is because she intended to make one of those kinds of things - not some other kind of artifact nor some non-artifact like a tree - but a violin. All of the artifacts around us prima facie result from an intention to make that kind of thing. It seems the intention-dependence condition is that artifacts are the products of an intention to make that kind of thing, where 'that kind of thing' is an artifact kind like chair, shoelace, pinball machine, whisk, carburetor, garlic naan bread, lithium ion battery, pencil, etc. ${ }^{12}$

We can formulate (IDA) as follows:

\footnotetext{
10 This example shows that intention-dependence isn't a sufficient condition, but only because Davies doesn't take actions to be artifactual events, as Evnine (2016) does.

${ }^{11}$ In English there is a distinct, technical use of 'artifact' to describe unintended effects of intentional activity as in 'pollution is an artifact of industrial production' or when archeologists describe a midden heap as an artifact of a previous culture. These are distinct uses of the term which fall outside the scope of this paper. See Dipert (1993, 33-37) for discussion. 12 It is an open and difficult question to say what makes a kind an artifact kind, but which kinds are artifact kinds is largely intuitive, which is where I will leave it.
} 


\section{Intention-dependence of artifacts (ID A): $x$ is an artifact of kind $K$ only if $x$ is the successful product of} an intention to make an artifact of kind $K$.

Since intentions are mental states that are always had by someone, it follows from (IDA) that artifacts have makers. ${ }^{13}$ The kind of dependence involved is rigid historical dependence. That is, a chair rigidly depends on its maker's intention to make it (no other agent could make that chair) and the chair bistorically depends on its maker's intention to make it (at some point prior to or coincident with its creation, its maker intended to make it). ${ }^{14}$ Artifacts don't constantly depend at every moment of their existence on their maker's mental states since it seems unassailable that artifacts can outlive their makers. The rigid historical dependence of artifacts on their makers is also constitutive rather than causal, i.e. the maker's intention to make a $\mathrm{K}$ partly constitutes what it is to be a K. Since the maker's intention also partly causally contributes to the existence of the $\mathrm{K}$, constitutive dependence entails causal (existential) dependence. By contrast, we can't infer that causal existential mind-dependence entails constitutive mind-dependence since I may intentionally plant an acorn which grows into an oak tree and am thus partly causally existentially responsible for the oak tree, i.e. its existence causally depends on my intention to plant the acorn, but that intention doesn't constitute the acorn or oak tree. ${ }^{15}$

As I've formulated it, (IDA) is quite simple. It says nothing about the content of the maker's intention nor what conditions are required for success. There have been more sophisticated refinements of (IDA) in the literature. For example, Thomasson $(2003,2007,2014)$ has argued that makers require a concept of the thing they intend to make - a concept of Ks - but moreover that their concept must be substantive and substantively correct. To borrow an example from Paul Bloom (1996), if I intend to make a chair and push some dirt into a little pile, I haven't made a chair partly because it seems that my concept of chair is substantively incorrect - I don't know what features are relevant to or constitutive of, chairs. Since chairs are generally intended for sitting on, I've failed to make a chair in part, it seems, because my creation can't be sat on. If I don't think chairs are for sitting on or if I don't intend to make something with other features relevant to being a chair (having legs and a back, say), then I lack the requisite concept of chairs. From this, it seems that to be successful, not only do I need a substantively correct concept of the kind of thing I'm trying to make, but also that

\footnotetext{
${ }^{13} \mathrm{Mag}$ Uidhir (2013, ch. 1) argues, in the context of what art is, that intention-dependence entails attempt-dependence since I can intend to make something but I won't succeed (i.e. satisfy my intention) unless I actually attempt to do so. Thus, attempting to $\Phi$ entails intending to $\Phi$ but not vice versa. My focus is on intention-dependence, rather than attemptdependence.

14 See Thomasson (1999, ch. 3), Evnine (2016, 86-96), and Irmak (2020) for discussion of this kind of dependence.

15 See Rosen (1994), Thomasson (2007) and Elder $(2007,2014)$ for discussion of the relevant sorts of dependence.
} 
my creation match that concept to some degree or other. What exactly the appropriate degree of fit is between my concept and creation for my intention to be successful is certainly going to vary by kind and context. I can succeed in making a cake even if what I produce is quite far from the recipe I was trying to follow. But to successfully make a transistor radio, say, my creation has to match my concept pretty closely, especially with respect to function. ${ }^{16}$ How exactly we should specify the content of makers' intentions or the success conditions for artifact creation doesn't matter for the purposes of this paper, so I'll leave (IDA) in its simple, unembellished form. ${ }^{17}$

Finally, note that my assumption that artifacts can be created by appropriation is compatible with (IDA). Since appropriation does a lot of work later in this paper, it's worth briefly explicating it here. Creation by appropriation isn't outlandish. Walk into any artisanal modern furniture store and they're likely to have unaltered pieces of driftwood for sale as wine racks or sculptures or coffee tables. Similarly, I may bring a rock in from the garden to be used as a doorstop or a paperweight or as Scheele (2006) discusses, a church may be appropriated as an event hall without altering the building. In such cases, it seems that a pre-existing object is appropriated as, and thereby becomes, a new artifact. In the case where I move a piece of driftwood from the beach to my kitchen to be a wine rack, I intend to appropriate it as a wine rack, which in turn can be understood as intending to make something of that particular artifact kind. Thus, there's still the relevant intention to make a $\mathrm{K}$, as (IDA) requires.

Often, we are willing to modify the object if necessary or desirable in order to serve our practical goals, but sometimes no modification is necessary. For example, I can appropriate a beautiful rock as a paperweight that's naturally been worn smooth by erosion; no modification is required on my part beyond moving it to my desk. However, if the rock has a knobbly protrusion on one side that unbalances it, I may knock this bit off so it functions better as a paperweight. Most artifacts we encounter in our daily lives have been modified in this way. That is, a bunch of pre-existing objects have undergone intrinsic physical modification in the process of an agent making an artifact, e.g. a bunch of wood is cut, sanded, and varnished to make a table. Creating an artifact by appropriation doesn't require this sort of intrinsic modification. In appropriating a piece of driftwood as a wine rack,

${ }^{16}$ While function is often central to artifact kinds, I don't want to commit myself to function essentialism. See my (Juvshik 2021) for discussion. Moreover, we need to take care in how we formulate the success conditions because we don't want to exclude malfunctioning artifacts. A chair with a broken leg is still a chair but in some circumstances malfunction can be so bad that the artifact has ceased to exist. Where to draw the line here is certainly going to be vague and probably contextdependent.

${ }^{17}$ For further discussion of (IDA) and success conditions, see Dipert (1993), Hilpinen (1992), Bloom (1996), Thomasson (2003, 2007, 2014), Baker (2007), and Evnine (2016). 
maybe I just dust off the sand from the beach. But this is only an extrinsic modification of the driftwood in the same way that moving the driftwood from the beach to my kitchen is only extrinsically modifying it. This suggests that a mere conceptual 'act' isn't enough to appropriate an object as an artifact. I can't just look at the driftwood and think it into a wine rack without doing anything else. At the least, I need to move it to my kitchen and use it as a wine rack. ${ }^{18}$ As a corollary, appropriation often seems to involve function - we appropriate objects as means to particular ends. If the object can't perform the intended function, or if it performs it very poorly, then the appropriational act will likely fail. I can't appropriate a tree branch as a combustion engine. The physical properties of the object must be such that it can perform the intended function to some acceptable degree.

The intention to appropriate an object as a new artifact seems to involve an intention that its use not be temporary. Ordinary English marks a distinction between 'being a K' and 'being used as a $\mathrm{K}$ '. The intention needs to be 'transformative' in some sense, i.e. I intend to make a $\mathrm{K}$ not just use something as a K. In case it's objected that cases of appropriation are just cases of the latter, as Dipert (1993, 26-27) and Evnine (2016, 132-133) argue, note that this is only sometimes plausible. A one-off use of my coffee mug as a paperweight intuitively doesn't make it a paperweight, but moving the driftwood from the beach to my kitchen as a wine rack, using it as a wine rack, and having everyone in my house accept it and treat it as a wine rack, seems to genuinely make it a wine rack. ${ }^{19}$ It may be indeterminate when mere use becomes genuine creation, but there are clear cases of each. ${ }^{20}$ In many contexts, it seems that some degree of social acceptance or recognition is needed - my family accepts the driftwood as a wine rack and treats it accordingly. Moreover, they would be subject to rebuke if they didn't treat it as wine racks are supposed to be treated by, e.g., moving it back to the beach or throwing it on a bonfire. Appropriating a natural object as an artifact may be easier than appropriating an existing artifact as a new member of a distinct artifact kind. This is perhaps why using my coffee mug as a paperweight, however regularly I do so, intuitively fails to make it a paperweight. $^{21}$

\footnotetext{
18 Borgo and Vieu (2009) seem to take a mere conceptual act as sufficient. By contrast, Mag Uidhir (2013) argues that (IDA) alone isn't sufficient for being an artifact or artwork; an attempt is also required and thus artifacts are attemptdependent as much as intention-dependent, with the former entailing the latter but not vice versa. This also holds for creation by appropriation, though the sorts of 'attempts' may be quite different.

${ }^{19}$ Eaton (1969) seems to suggest that any amount of use, however one-off, is sufficient to make something into a K.

${ }^{20}$ Van Inwagen (1990) argues that such indeterminacy impugns the ontological respectability of artifacts and other ordinary objects, but I won't pursue that issue here.

21 There may be relevant differences in the kind of appropriation between the driftwood wine rack and the church event hall or the coffee mug paperweight. These may include whether the object is already an artifact, whether the use is intended to be temporary, whether the appropriation occurs in a social context, and the intentions of the appropriating agent. Such distinctions may be used to formulated more refined versions of IDA (as well as counterexamples to it), though pursuing these issues is beyond the scope of this paper. I'll therefore conditionalize the arguments of this paper on appropriation being as I've so far described it.
} 
Nonetheless, if the relevant intention is present and there's general social acceptance of the maker's success, existing artifacts can become new artifacts as with, say, a lampshade that's turned upside down as a birdbath. ${ }^{22}$

Appropriation is therefore sufficiently clear, well-understood, and accepted widely enough for the purposes of this paper, although much more could be said about it. Moreover, (IDA) looks like a plausible necessary condition on being an artifact and it is prima facie extensionally adequate. Now that (IDA) is formulated (and appropriation is explicated), we can consider the two separate challenges to it: (1) that artifacts aren't necessarily mind-dependent, they just often are and (2) that while artifacts are necessarily mind-dependent, they aren't necessarily intention-dependent. I consider these respective views in the following two sections.

\section{Artifacts and Mind-Independence}

It may be argued that while most of the artifacts we encounter are clearly the result of intentional activity, they need not have been - the exact same object could have come into existence in some other way. ${ }^{23}$ This kind of scenario is often brought up in the literature on composition, especially when talking about the problem of the statue and the clay.

There are two general kinds of cases that are sometimes taken to show the possible (at least in principle) mind-independence of artifacts. First, are so-called swamp cases, first introduced by Davidson (2001) but not about artifacts, and second are modal cases involving far-flung possible worlds devoid of minds and mental states. These cases elicit some intuitions that the objects described are artifacts but no minds are involved, so these are counterexamples to (IDA). For example, Muhammad Khalidi writes that, "However, improbable it may be, it seems obvious that a building, canoe, broom, or shoe could all have materialized on a planet in which there never were any humans or other intelligent beings" $(2016,232) .{ }^{24}$ Focusing on this claim, consider the following pair of cases:

Swamp Car: A tree in a swamp is struck by lightning and its broken down into its component atoms which then coalesce into an object that is intrinsically identical to a 2006 Honda Civic.

\footnotetext{
22 Appropriation of existing artifacts may overlap with the concepts of reusing and recycling. Scheele (2006, 59) gives the example of a figure-eight belaying device that's appropriated as an abseiling device by the climbing community, while Thomasson (2014, 53-54) gives a fictional example of Americans appropriating chopsticks exclusively as hair ornaments. 23 Such a view would deny that mind- and intention-dependence are constitutive of being an artifact, but rather only (sometimes) causally contribute to their existence. See Lowe $(2014,20)$.

24 See also Elder $(2007,2014)$ for important discussion and defense of the mind-independence of artifacts. Often what's motivating mind-independence accounts are concerns about realism. See Soavi (2009) for discussion of this connection.
} 
Isolated Car: In a remote possible world there exists nothing, including no minds or mental states, except a single object that is intrinsically identical to a 2006 Honda Civic.

Both cases involve an object that is qualitatively identical to a certain kind of artifact, namely a 2006 Honda Civic, though the exact kind of artifact is irrelevant. The question is whether these objects are artifacts. Some philosophers have the intuition that these objects are cars and infer from this that they're artifacts. Hence, they accept the inference that being a member of a particular artifact kind entails being an artifact. ${ }^{25}$ Since the existence of the putative artifact in no way depends on minds or mental states, then these cases are counterexamples to (IDA) and the question now becomes what to make of the intuitions to the contrary. ${ }^{26}$

I don't share this intuition, but as philosophers, we're almost certainly subject to theoretic bias. The role of intuitions in philosophy is complicated and it's unclear to what extent we should weigh them in such cases. I consider two approaches to handling this dispute. First, these cases can be treated as 'spoils to the victor'. While I prefer this approach, I also sketch a series of error theories that aim to explain why someone would have the intuition that the objects in the two cases are artifacts despite the fact that they're not artifacts. These two approaches are compatible with one another.

\subsection{Spoils to the Victor}

One way to adjudicate this clash of intuitions is to treat it as a case of 'spoils to the victor'. That is, what we should say about Swamp Car and Isolated Car is whatever our preferred theories say about them. If I have a theory that says these objects aren't artifacts, then that's all I need to say about such cases. The motivation for this approach is that the cases themselves are so fringe or far afield compared to other cases involving artifacts that intuitions aren't reliable so whatever theory turns out to be the best theory will entail an answer about Swamp Car and Isolated Car.

David Lewis $(1986,194)$ appeals to similar considerations in the context of causation, crediting David Armstrong with the phrase 'spoils to the victor':

\footnotetext{
25 Some may have the intuition that these objects are cars but deny that they're artifacts. This treats car and other subkinds as purely functional kinds, members of which may or may not be artifacts. There are two things to note about this. First, this would just deny that these are counterexamples to (IDA) since they're not artifacts. Second, it's very difficult to spell out a story whereby these objects actually have the functions they intuitively do as artifacts. All of the main theories of function will either over-attribute function, so that there are far more functions in the world then we would intuitively recognize, or under-attribute function such that Swampcar wouldn't even have a function. I therefore set this line of reasoning aside. 26 Similar cases can be constructed for species kinds since a prevalent view of species is that they're determined by their causal-historical history of reproduction. Burgess and Rosen $(1997,21)$ also make this point, though in a different context. In Davidson's (1987) original version with Swampman, the issue was whether Swampman could be said to possess certain concepts or propositional attitudes since they didn't come about in the right causal-historical way.
} 
When common sense delivers a firm and uncontroversial answer about a not-too-farfetched case, theory had better agree. If an analysis of causation does not deliver the common-sense answer, that is bad trouble. But when common sense falls into indecision or controversy, or when it is reasonable to suspect that far-fetched cases are being judged by false analogy to commonplace ones, then theory may safely say what it likes. Such cases can be left as spoils to the victor, in D. M. Armstrong's phrase.

What Lewis is saying is that we should treat common sense intuitions as reliable if they yield a clear pronouncement in what we might call 'ordinary' cases. However, if a case is so far-fetched then we might suspect that our intuitions are no longer reliable. We may be tacitly comparing the far-fetched case to ordinary cases and due to perhaps superficial similarities between the two, treating them as analogous. Given such a far-fetched case, whatever pronouncements a theory has about it is good enough.

This is my preferred approach. Isolated Car is, by stipulation, impossible for us to encounter, while Swamp Car is so fantastically unlikely that there's no reason to think our intuitions about it would be reliable. Thus, after competing theories give way to a clear best theory, whatever that theory says about such cases is what we should accept. Hence, such cases are best treated as spoils to be won by our best theory.

\subsection{Three Error Theories}

While I'm content to treat Swamp Car and Isolated Car as spoils to the victor, not everyone may be satisfied with this approach. Additionally, I'll offer three potential error theories for why some philosophers have the intuition that the objects in Swamp Car and Isolated Car are artifacts. ${ }^{27}$ The three error theories below aren't mutually exclusive; someone's intuition may be influenced by one or more of them. ${ }^{28}$

\section{First Error Theory}

Following Paul Bloom $(1996,21)$ we can say that intuitions may be swayed by superficial features such as form. Because the objects in Swamp Car and Isolated Car are stipulated to have the exact same shape as a 2006 Honda Civic, we might think this indicates that these objects are cars, so ipso facto artifacts. Lay people often take form to be an essential feature of a given artifact kind, so to be a 2006

\footnotetext{
${ }^{27}$ By 'error theory' I don't mean the notion associated with J. L. Mackie (1977), whereby an entire domain of discourse is systematically false, but rather an explanation for a particular intuition the content of which is false.

28 An additional factor influencing intuitions may be how the cases are described. Using the term 'car' in the names of the cases may suggest that it is a car.
} 
Honda Civic is (in part) to have this particular form. ${ }^{29}$ While I can't fully argue against form-theoretic accounts of artifact essences, at present it's enough to say that such superficial features can lead to erroneous intuitions about kind membership.

This is similar to how we may erroneously categorize certain natural kinds prior to more sophisticated scientific understanding about them. If we were presented with Putnam's Twin Earth case prior to 1750 , then we would probably have the intuition that $\mathrm{XYZ}$ is of the same kind of stuff as $\mathrm{H}_{2} \mathrm{O}$. In the same (mineral) vein, jadeite and nephrite were taken to be of the same mineral kind in virtue of their shared superficial features like colour, texture, and durability, but once we discovered that they had very different molecular structures we realized our error. In the case of artifacts, we do something similar. This isn't surprising, since we usually identify artifacts by their form, e.g. I know this is a car because it looks like stereotypical cars do. Thus, in Swamp Car and Isolated Car we are swayed by a shared form into categorizing these objects as artifacts when they in fact aren't.

\section{Second Error Theory}

A second, related explanation is that we are swayed by apparent complexity, seeming non-randomness, and appearance of intelligent design into tacitly attributing intentional creation despite it being explicitly stated in the cases that none is involved. That is, such objects look like they were intentionally made because they look exactly like cars that we're familiar with and know are intentionally made. Such a complex object is unlikely to have come into existence naturally so we may be assuming some kind of intention-dependence. Again, this may influence our intuitions such that we implicitly think that there is some intention involved despite the cases stipulating that there are no minds or mental states that the objects depend on.

Bloom (1996, 21-22) also suggests this explanation. Intuitions may differ depending on the complexity of the object described. Intuitions that Swamp Car is a car may be very strong because the object is highly complex and thus more likely to have been created. But if we replaced Swamp Car with Swamp Toothpick intuitions will probably be weaker. A toothpick doesn't have the same degree of complexity and so an object is more likely to non-intentionally resemble a toothpick than a car. This is similar to the Argument from Design: we assume that nature must have a designer because it appears to be so complex and non-random, like a watch, thus we posit a deity as its maker. In Swamp Car and Isolated Car we are doing something similar: the objects are described as resembling genuine cars,

${ }^{29}$ Form or structure is often combined with function as potential artifact essences; see e.g. Elder (2007), Soavi (2009), and Franssen and Kroes (2014). See the third error theory, below, for function. 
which are very technically complicated, so we implicitly assume that they have makers even though the cases stipulate that they don't. ${ }^{30}$

\section{Third Error Theory}

A third error theory of such intuitions is that they are in fact cases of tacit or potential appropriation. A rock can genuinely become a doorstop with the right intentions, use, and communal acceptance. Assuming the genuine occurrence of appropriation, we can use it to explain other phenomena, including explaining away intuitions in Swamp Car and Isolated Car. Such objects are intrinsically like a car, so in imagining them we imagine interacting with them as we would with an actual car and they function just like one. Thus, we are tacitly projecting what Wybo Houkes and Pieter Vermaas (2004, 57ff.) call 'use plans', which are "a goal-directed series of considered actions, a use plan of an object $\mathrm{x}$ is a series of such actions in which manipulations of $\mathrm{x}$ are included as contributions to realizing the given goal". In wondering whether Swamp Car and Isolated Car are artifacts despite not having makers, we imagine using them as we would any other car; we could open the 'door', turn the 'key' and drive out of the swamp, etc. Because they can be so used (in virtue of their intrinsic properties) we develop the intuition that they are artifacts. Thus, we are conflating the potential use of such objects with their being artifacts. Both cases are stipulated to not involve any minds or mental states and in Isolated Car it's stipulated that that world doesn't even contain any. However, in imagining the cases we're projecting an intentional perspective - our own - on those worlds and thereby undermining the stipulation. We can't help but imagine ourselves in relation to those objects, e.g. sitting behind the 'wheel'.

Sure, such objects can become artifacts if the conditions are appropriate, but merely imagining the cases isn't sufficient for such appropriation. If I came across Swamp Car and put gas in it and drove it out of the swamp, then this might be enough to make it a car (or perhaps some amount of acceptance of it as a car by my social group would also be required). But merely having the potential to be appropriated as a car doesn't make Swamp Car a car from the moment it comes into existence. Thus, in imagining the cases we can't help imagining how we would interact with the object as if it's a car, even though it isn't one.

\footnotetext{
${ }^{30}$ Relatedly, Schaffer and Rose (2017) argue that folk mereology is teleological, so intuitions will assume that there's some purpose to such objects, while Hughes (2009) argues that artifact functions are teleological. See also Korman and Carmichael (2017). Similarly, Kelemen (1999) has shown that there's a bias towards over-attributions of agency in children.
} 
While I find all three error theories plausible, I'm not ultimately concerned with defending them since I'm content with the spoils to the victor approach. Therefore, we can safely set these cases aside as counterexamples to a general mind-dependence condition on artifacts. In the absence of other counterexamples, we can retain (IDA) and the general mind-dependence of artifacts.

\section{Artifacts and Intention-Dependence}

Rather than denying the mind-dependence of artifacts, one may accept it but deny that artifacts are necessarily intention-dependent. Instead of being motivated by esoteric metaphysical considerations, this view points to aspects of our actual artifact practices. There are three general sorts of cases that suggest the mind-dependence sans intention-dependence of artifacts. First, are cases of putative accidental making, second, cases of automated production, and third, cases of mass production. I discuss each in turn and argue that none of them constitutes a counterexample to (IDA) because intentions are present, just not where we might initially expect.

\subsection{Accidental Making}

The first kind of case are cases of putative accidental making. Some cases may appear to show that one can make an artifact accidentally, i.e. without intending to do so. There are two different kinds of cases of accidental making, which illustrate the same apparent phenomenon. First, are historical cases of alleged accidental creation of some artifact or artifact kind:

Post-it Note Adhesive: Spencer Silver was intending to make a strong industrial adhesive but the result was an adhesive that couldn't physically attach things together in a permanent or reliable manner. However, the adhesive was trademarked and about ten years later Art Fry had the idea of applying it to the back of pieces of paper. The properties of the adhesive allowed the pieces of paper to be easily applied and removed repeatedly from hard surfaces. Thus, was born the post-it note. ${ }^{31}$

Since Silver intended to make an industrial-strength adhesive and not post-it note adhesive, it seems like he made post-it note adhesive without intending to do so. There are many other examples like this from the history of technology, such as slinkies.

A second kind of example that suggests the same thing involves no intention to make anything, unlike the creator of post-it notes who intended to make an industrial-strength adhesive. Consider the following case:

Sophie the Clutz: Sophie, who is very clumsy, is walking through her garage when she

\footnotetext{
${ }^{31}$ For details, see Petroski (1992, 84-86).
} 
bumps into a table, knocking a pile of wood to the floor and throwing a jar of wood glue into the air. Some of the wood glue lands on parts of the scattered wood and the wood falls such that various pieces are attached together by the glue. The result is an unlikely but sturdy structure resembling a standard dining room chair. Sophie, finally profiting from her clumsiness, takes herself to have accidentally made a chair, which she brings inside to sit on.

Like the historical cases, Sophie the Clutz seems to be a case of someone making an artifact without any intention to do so. In both cases, the resulting artifact (post-it note adhesive and a chair, respectively) are mind-dependent insofar as their existence depends on a mind and mental states but aren't intention-dependent insofar as the minds they depend on didn't intend to create them. In neither case does it appear that the creators have an intention to make that kind of thing, although they may have other intentions that ultimately causally contributed to the production of an artifact. These cases appear to be counterexamples to (IDA). ${ }^{32}$

\subsubsection{Cases of Appropriation}

While these cases may appear to show that some artifacts can be made accidentally, i.e. unintentionally, I think both kinds of cases in fact involve intentions to create something, just not where we'd normally expect. Take the case of post-it notes and other historical 'accidental' inventions. Spencer Silver intended to make a strong adhesive. His intention either failed such that the result was a failed (non) industrial adhesive or we can understand him as making a very poor industrial adhesive. Regardless, the resulting product had the physical properties to perform some other function, namely, to easily be applied and reapplied to various surfaces. While the creator's initial intention failed or wasn't well executed, later, Art Fry had an intention to apply the adhesive to the back of paper in order to create post-it notes. This occurred a decade after the initial invention of the adhesive. This later intention to make post-it notes was successful and post-it notes were thereby created. The initial intention to make a strong adhesive wasn't an intention to make post-it notes so is irrelevant to their existence (except insofar as the failed product of that intention allowed the invention of post-it note adhesive). The relevant intention is Fry's much later one.

We can say the same thing in the case of Sophie the Clutz: Sophie had no intention to make anything, she was just moving through the garage. However, through various movements and coincidences, her actions led to various material objects coming to be shaped just like a standard chair,

32 Friedell (2016, 2017), Brock (2017), Cray (2017), and Goodman (2020) raise similar cases of accidental creation as counterexamples to (IDA). 
none of which was intended by her. However, later she realized that her clumsiness resulted in something chair-shaped and she intentionally decided to move it into the house and use it as a chair. It is this subsequent intention that resulted in the creation of a chair out of the mess that she made. There wasn't any initial intention to arrange the wood and glue in such a chair-shaped way, but once it was so arranged, however it came about, Sophie intended to use the resulting object as a chair and moved it into her house to do so. So again, there is a relevant intention involved, it's just not where we might expect it to be in normal cases of artifact creation.

Once we recognize what the relevant intention is that resulted in the creation of the artifact, we can see that such cases of 'accidental' creation are really cases of appropriation. Appropriation is taking a pre-existing object and making it into an artifact without modifying it, like moving a rock inside from the garden to become a doorstop. The adhesive and arrangement of wood and glue both had the potential to become post-it note adhesive and a chair, respectively, but when they initially came into existence they weren't members of those kinds. The subsequent intention that Fry and Sophie had to appropriate the adhesive and the wood-and-glue arrangement as post-its and a chair, respectively is what made them into those particular artifacts. ${ }^{33}$

\subsubsection{An Alternative Explanation: Accidental and Incidental Creation}

One may reject my explanation of the previous cases as cases of appropriation by arguing that they're better understood using Dominic McIver Lopes' (2007) distinction between accidental and incidental creation. Lopes argues that makers can create artifacts accidentally, where they unintentionally create something in virtue of failing to make something else, or incidentally, where they unintentionally create something in virtue of succeeding in making something else.

Lopes defines accidental making as follows $(2007,8)$ :

Accidental making: $S$ accidentally makes an $F$ just in case $S$ intends to make a $G$, an $F$ is not a $G, S$ fails to make a $G$, and in failing to make a $G, S$ makes an $F$.

\footnotetext{
${ }^{33}$ How we understand Silver's original intention might matter here. If Silver failed to make an industrial adhesive, then Fry appropriated a non-artifact as the prototype member of a new artifact kind. If Silver succeeded in making a very bad industrial adhesive, then Fry appropriated a pre-existing artifact, which happened to be a poor member of its original kind, as the prototype member of a new artifact kind. In general, it seems more difficult to appropriate pre-existing artifacts as new artifacts than it does to appropriate natural objects like a piece of driftwood or a rock. See Scheele (2006, 28-29) and Thomasson (2014, 53-54, n9) for discussion of these sorts of cases. Given the properties of Spencer's adhesive, I'm inclined to say that he failed to make an industrial adhesive.
} 
For example, I try to make a loaf of bread, fail such that it's hard as a rock and inedible, but I've succeeded in making a doorstop. I didn't intend to make a doorstop, I intended to make bread, but I made a doorstop accidentally.

Lopes defines incidental making as $(2007,9)$ :

Incidental making: S incidentally makes an F just in case $S$ intends to make a $G, S$ does not intend to make an F, $S$ makes a $G$, and in making a $G, S$ also makes an $F$.

For example, the Chinese intended to make black powder for fireworks but in so doing made gunpowder. The Chinese intended to make black powder, succeeded in making black powder, didn't intend to make gunpowder, but since black powder is gunpowder, they incidentally made gunpowder.

Is this a superior explanation of cases of putative accidental making? No, for several reasons. First, note that the case of Sophie the Clutz satisfies neither incidental nor accidental making. Since there was no initial intention to make anything, it doesn't look like it maps onto Lopes' distinctions, since both require an intention to make a G; Sophie didn't intend to make anything with her clumsiness. Perhaps Lopes could claim that Sophie's intentionally walking through the garage could be substituted for ' $G$ ', and thus there was an intention to do something. But this won't work because first, what results from the walking is the wood and glue arrangement which I argued is later appropriated as a chair. It's the wood and glue arrangement that should be substituted for 'G', not the walking. Second, Sophie's walking didn't fail - she successfully walked through the garage, if clumsily - so this wouldn't satisfy accidental making. But nor would it satisfy incidental making since a walking is not a chair. Lopes' distinction can't handle Sophie the Clutz, so her creation of a chair is better understood as a case of appropriation.

Further, Lopes' formulations involve an implicit assumption that the failure/success to make a G happens simultaneously with the successful creation of an F. ${ }^{34}$ But it's highly counterintuitive that the failed bread is simultaneously a doorstop at the moment of the failure. Rather it is a subsequent intention to make a doorstop that makes the doorstop. This distinct intention may or may not occur simultaneously with the failure to make a load of bread. Perhaps the would-be bread maker

\footnotetext{
${ }^{34}$ Xhignesse $(2020,909)$ rejects the possibility of accidental artifacts but argues that incidental artifact creation is possible. He also seems to assume that an F is created simultaneously with the creation of a $G$ - he gives the example of failing to pitch a tent but incidentally creating an abstract sculpture. Like Lopes' cases, we can treat the creation of the abstract sculpture as a subsequent appropriation of the failed tent pitch.
} 
immediately intended to use her failure as a doorstop but she needn't have done so. ${ }^{35}$ Indeed, the vast majority of failed loaves of bread aren't doorstops; only in cases where there is an intention to make a doorstop out of a bad loaf of bread do we get a doorstop, in which case it's clearly appropriation.

This is also the case with post-it note adhesive. What Silver produced didn't immediately result in the creation of post-it note adhesive. Depending on how we understand Silver's intention, either a bad adhesive was created or he produced a failed adhesive but either way, post-it notes and post-it note adhesive weren't created until a decade or so later when Art Fry had the intention to apply it in this sort of way for this kind of use which is best understood as Fry appropriating Silver's product. ${ }^{36}$

Similarly, in the case of the incidental making of gunpowder, Lopes again assumes that the creation of an $\mathrm{F}$ is simultaneous with the creation of a $\mathrm{G}$. We can say similar things about gunpowder that we said about post-it notes and doorstops. Gunpowder only satisfies incidental making if it comes into existence simultaneously with black powder. But such simultaneous creation seems counterintuitive. The Chinese invented black powder to be used in fireworks. It was a later intention to use it to propel projectiles for warfare - developed in conjunction with the creation of firearms and artillery - that resulted in the creation of gunpowder. The creation of black powder didn't immediately involve the incidental creation of gunpowder. Indeed, if black powder was invented and then all intelligent life died, it seems implausible to claim that gunpowder was invented, partly because gunpowder seems to depend on the simultaneous development of guns, without which there was no such thing as gunpowder. It was the subsequent intention to use black powder in warfare using these kinds of weapons that resulted in the creation of gunpowder. ${ }^{37}$ As a result, explaining cases of putative accidental creation as cases of appropriation is the better explanation.

\footnotetext{
35 It's also not obvious that bread and doorstops satisfies Lopes' accidental making because in some cases perhaps a successful loaf of bread can be a doorstop, hence the 'an $F$ is not a G' condition isn't always satisfied.

${ }^{36}$ In case it's objected that post-it note adhesive came into existence at the moment of failure, note two things. First, while the adhesive was patented at the time of failure (or shortly thereafter), if all intelligent life on the planet immediately ceased to exist we wouldn't say that post-it notes had been invented. Moreover, the patent was just for the adhesive; a subsequent patent was given for post-it notes. Second, we can't claim that this particular adhesive is type-identical to post-it note adhesive because there are in fact multiple chemically distinct adhesives that are used in post-it notes that have similar properties. The particular pressure sensitive acrylate that was patented by $3 \mathrm{M}$ doesn't fix the reference of 'post-it note adhesive' because post-it note adhesive is multiply realizable. See 3M (1999).

${ }^{37}$ It can't be objected that gunpowder just is this particular chemical composition. First, there's no single ratio of sulfur, saltpeter, and charcoal; different ratios were used for different kinds of weapons by different nations over the past thousand years or so. Second, the original mix invented by the Chinese of sulfur, saltpeter and charcoal is not the only chemical mixture used in this way. Variations include various so-called brown powders (as opposed to smokeless black powder) which use different kinds of nitrates or are sulfur-free. Gunpowder is multiply realizable. See Kelly (2004) for the history of gunpowder and the National Research Council report (1998) on black and smokeless powders for their chemical composition.
} 


\subsection{Automated Production}

The second kind of case that may suggest (IDA) is false are cases of automated production. The paradigm case of artifact creation is the lone artisan in her workshop weaving a basket or constructing a bedframe. But the vast majority of artifacts around us are the result of mass production - huge factories employing hundreds or thousands of people in tightly controlled and delegated tasks. Increasingly, mass production is being automated. This is especially so where the artifact is extremely technical and complicated, such as aircraft production or computer chips.

Automated production is highly mechanized, where various robotic parts are designed and programmed for a single task. In such cases, it looks like an artifact is produced but the producer is a collection of robotic components governed by a computer program which directs their function. This prima facie seems to present a counterexample to (IDA). Consider a relatively simple (and simplified) case: frozen yogurt. ${ }^{38}$ Commercially produced frozen yogurt typically consists of a mixture of milk fats and solids, sugar, gelatin, air, water, and egg solids, in addition to various flavour additives and preservatives (Goff and Hartel, 2013, 55ff.). These ingredients are measured, heated and mixed in vats, then pasteurized and homogenized, inoculated with yogurt culture and cooled. (ibid. 157-167). This process is mechanized and almost entirely automated, ${ }^{39}$ other than manually loading ingredients or the final product for shipping. ${ }^{40}$ Thus, it looks like frozen yogurt can be created without any intention to do so.

We can distinguish between two kinds of cases of automated production: first, those produced with sophisticated artificial intelligence (AIs) and second, those that are just governed by simple computer programs. In the case of AIs, if they're sufficiently sophisticated, then there is a direct intention to create frozen yogurt, or a car or whatever. While our technology is not yet sophisticated enough to produce AIs to whom we would attribute intentionality and other propositional attitudes, including an intention to $\Phi$, major strides have been made and it seems likely that they will exist in the relatively near future. If the AI is a genuine agent, as we are stipulating, then it has mental states and the capacity to intend to act, including the ability to intend to make a $K$, where ' $\mathrm{K}$ ' is an artifact kind. Ipso facto, there is a readily identifiable intention to produce the frozen yogurt, since the automated

\footnotetext{
38 See Arthur (2009) for general discussion of automated/mass production and technological development.

39 As Goff and Hartel $(2013,8)$ report, the number of factories producing frozen dessert products in the U.S. dropped from 1628 in 1970 to 400 in 2000, while production has simultaneously increased dramatically between those years, mostly due to automation.

40 There are, of course, still human quality testers and safety inspectors, but these aren't involved in production. See Goff and Hartel (2013, ch. 14).
} 
processes are directly governed by the AI. Thus, the frozen yogurt is the product of an intention to make frozen yogurt. ${ }^{41}$

In the case where the programs aren't that sophisticated, then there's an indirect intention to create an artifact. (IDA) doesn't require that the intention to make a $\mathrm{K}$ be direct, i.e. I do something which is the proximate cause of the existence of a $\mathrm{K}$. In the case of automated production, the makers and designers of the frozen yogurt factory intend to make an automated frozen yogurt factory, and are thereby intentionally making frozen yogurt in virtue of intending to make an automated factory that will make frozen yogurt. Makers of frozen yogurt want to make frozen yogurt. There are many ways to achieve this goal. One such way, which is especially fruitful given the desire to mass produce frozen yogurt, is to automate production. Thus, the makers of frozen yogurt see the various automated components of the production line as a means to an end. The makers have an indirect intention to make frozen yogurt by having a direct intention to do various other things such as building a production line in this particular way, governed by these particular programs and components, all of which has the foreseeable and intended consequence of producing frozen yogurt. Therefore, we can identify an intention to make frozen yogurt, it's just not governing the most immediate causally responsible event that produces the frozen yogurt. However, that intention is governing the many component activities that go into the production of the frozen yogurt. ${ }^{42}$ As a result, automated production isn't a counterexample to (IDA). ${ }^{43}$

\subsection{Mass Production}

It could be objected that much of our current mass production isn't fully automated, but involves a mixed production process of human line workers and mechanized components. This often involves situations like the following one described by Hilary Kornblith $(2007,145)$ :

\footnotetext{
${ }^{41}$ A related putative counterexample to (IDA) may be animal artifacts like termite mounds, beaver dams, and bird nests. I will follow Thomasson $(2007,67)$ in treating this as an empirical question for the relevant animal experts. If it's determined that some species has genuine intentions, then their products will count as artifacts just as much as alien or AI artifacts would. If they don't have the capacity to intend, then their products are not artifacts properly so-called, but may be described as 'artifacts' in a technical, scientific sense. See Gould (2007) for discussion.

42 See Hilpinen (1992, 60n7) and Dipert (1993, 126-129) for further discussion of 'indirect' intentions in this context. See also Bratman (1987) for discussion of indirect intending and means-end reasoning.

${ }^{43}$ One could argue that the way I've bifurcated the cases ignores a middle possibility where we have a machine learning algorithm that through various inputs teaches itself to make frozen yogurt, but which isn't as sophisticated as full-blown AIs that would count as persons. Does such a program have genuine intentions? Ultimately, what we say in this case depends on our theory of mind. However, we can say that the stuff produced by such an algorithm isn't initially frozen yogurt but could be appropriated as frozen yogurt by subsequent agents or we can compare this case with common cases of inventors messing around by going through trial and error with their creations. Whoever programmed the algorithm could be understood as relying on a sort of chancy process to produce artifacts.
} 
Consider the case of Harry, who works in the Acme Carabiner Factory. Harry stands at his machine, day after day, making carabiners. He is a maker of artifacts if anyone is. But Harry has no substantive concept of carabiners. If asked what it is he makes, Harry will say: 'I don't know what the devil carabiners are for. As far as I'm concerned, they're just something that puts food on the table.'

The case of Harry looks like a case where Harry doesn't have an intention to make carabiners - he can't have that intention because he doesn't know what carabiners are - yet Harry is making carabiners, so (IDA) is false. ${ }^{44}$

We can't say the intention is indirect here since Harry doesn't know what carabiners are. But Harry's role in the production line does give us a clue as to how to understand this kind of case. Harry is partially responsible for the production of carabiners in virtue of helping assemble them. Our talk of an artifact's 'maker' is ambiguous. It can mean any of the following:

(a) The person who designed the artifact

(b) The person who assembled the artifact

(c) The person who guided the assembly of the artifact according to the design plan ${ }^{45}$

In the romanticized case of the lone artisan in her workshop (a)-(c) will coincide. However, as artifacts have become increasingly more complicated and mass production has increased, (a)-(c) now often come apart. In the case of the artisan, she designs a wooden bed frame, guides assembly of the bed frame according to her own design plan, and directly assembles the bed frame. In the mass production of carabiners, the designer may never even set foot in the factory. There may be a production overseer who guides the production of carabiners, ensuring that assembly conforms to the design. Finally, the actual line workers are causally responsible for assembly, literally putting the pieces together into the finished product. This is the case with Harry: he's just an assembler. But that doesn't entail that carabiners aren't intention-dependent, only that the person assembling them need not be the person upon whose intention they depend. There is someone who intended to make a carabiner - the designer - they just didn't physically assemble them. In one sense, Harry is a maker of carabiners, but in another he's not the maker in the sense of being the origin of the intention to make carabiners. ${ }^{46}$ (IDA) is

\footnotetext{
44 Evnine (2016, 97ff, 2019) and Koslicki (2018, 234-235) also raise concerns about mass production in this context.

45 Evnine (2016) also distinguishes between the maker in the sense of the efficient cause of an artifact and the maker in the sense of the formal cause. The latter is the (a) sense of maker, on Evnine's hylomorphic view.

${ }^{46}$ Harry does, of course, have intentions that are guiding his actions in assembling the carabiner.
} 
thereby primarily concerned with the (a) sense of 'maker'. ${ }^{47}$ This isn't that different from automated production. While Harry isn't being programmed to make carabiners, he's still a means to the end of producing carabiners. Distinguishing between the different senses of maker, we see that Harry is a maker of carabiners, but not in the sense that concerns (IDA). As a result, cases of mass production aren't counterexamples to (IDA).

My response to cases of mass production is in many respects similar to Thomasson's response to Kornblith. Kornblith chiefly uses the case of Harry to show that makers may be completely ignorant of the things they make. ${ }^{48}$ While Thomasson (2007, 66-68) also distinguishes between different senses of 'maker', her concern isn't immediately with (IDA) but is foremost with defending the claim that makers have a certain degree of epistemic privilege with respect to their creations against Kornblith. Recall that Thomasson argues that makers require a substantive and substantively correct concept of the things they make. The case of Harry looks like a counterexample to such a condition because Harry is a maker of carabiners without knowing what they are (and thus having no substantive concept of them). But Thomasson's claim of epistemic privilege doesn't necessarily apply to assemblers, but to those whose intention is guiding assembly - the (a) or perhaps (c) sense of 'maker'. As a result, Thomasson defends a condition on makers' concepts, i.e. the content of their intention to make a K, whereas I'm concerned with defending the necessity of the intention itself.

\section{Conclusion}

Our practices of making, using, classifying, and appreciating artifacts suggest that they depend on the intentions of their makers. I've called this the intention-dependence condition of artifacts (IDA) and defended it against challenges from two directions: cases that suggest intention-dependence, and mind-dependence, generally, are only typical, but not necessary features of artifactuality and cases that purport to show that artifacts are necessarily mind-dependent but not intention-dependent. In the case of allegedly mind-independent artifacts, we can treat them as spoils to the victor, while also advancing potential error theories to explain away countervailing intuitions. In the case of alleged intentionindependent artifacts, such as post-it note adhesive and the results of automated and mass production, we can readily identify the relevant intentions, just not where we might initially expect.

\footnotetext{
${ }^{47}$ It's worth noting that (IDA) doesn't entail a single maker, even in the sense of (a). Supertall skyscrapers and the Large Hadron Collider are too complicated for a single individual to design. The (a) sense can involve multiple agents with coordinated intentions. The artifact, a skyscraper, say, still satisfies (IDA), there are just multiple agents with coordinating intentions to make a skyscraper. See Houkes and Vermaas (2004) for discussion of coordinating intentions in this regard. 48 See also Kornblith (1980).
} 
The defense of (IDA) goes some way towards understanding the metaphysical nature of artifacts, but as a purely necessary condition, there's still much to explore about what artifacts are. However, recognizing the role of intentions in artifact creation does give us a useful starting point for an epistemology of artifacts, technology, and other built aspects of the social world by providing a prima facie constraint on what kind an artifact belongs to, what it's for and what the proper way to use and regard it is. Since being an artifact necessarily involves being the successful product of an intention to make that kind of thing, makers are in a (at least initial) epistemically privileged position with respect to their creations - thereby to some extent vindicating Thomasson's arguments against Kornblith. Of course, much of the literature already assumes some version of (IDA). Therefore, my defense of (IDA) grounds an important starting point for both current and future metaphysical and epistemological inquiry into the nature of artifacts. However, those who approach a metaphysics or epistemology of artifacts with certain realist assumptions and are thereby skeptical of the reality of artifacts won't be swayed by anything I've said. One needs to accept mind-dependence as a respectable basis for metaphysics in order to appreciate my defense of (IDA) against extensional challenges. Rebutting metaphysical challenges to artifacts from realist quarters is a separate project.

Acknowledgements: Thanks to Phillip Bricker, Patrick Grafton-Cardwell, Sophie Horowitz, Hilary Kornblith, Justin Mooney, Alejandro Perez-Carballo, Sam Schechter, and Amie Thomasson for helpful comments and criticisms on this paper.

\section{References}

3M. “Adhesive in Post-it ${ }^{\circledR}$ Notes” Technical Bulletin no. 1 (August, 1999), Rueil-Malmaison, France.

Arthur, W. Brian. The Nature of Technology: What It Is and How It Evolves. New York: Free Press, 2009.

Baker, Lynn Rudder. The Metaphysics of Everyday Life. Cambridge: Cambridge University Press, 2007.

Bloom, Paul. "Intention, History, and Artifact Concepts” Cognition vol. 60 (1996): 1-29.

Borgo, Stefano and Laure Vieu. "Artifacts in Formal Ontology." In Philosophy of Technology and Engineering Sciences, ed. Meijers, 273-308. Amsterdam: Elsevier, 2009.

Brock, Stuart. “A Recalcitrant Problem for Abstract Creationism” The Journal of Aesthetics and Art Criticism vol. 76 (2017): 93-98.

Burgess, John and Gideon Rosen. A Subject with No Object. Oxford, OUP: 1997.

Cray, Wesley. "Abstract Generationism: A Response to Friedell” The Journal of Aesthetics and Art Criticism vol. 75 (2017): 289-292. 
Davidson, Donald. “Knowing One’s Own Mind.” In Subjective, Intersubjective, Objective, 15-38. Oxford: OUP, $2001 / 1987$.

Davies, Stephen. Definitions of Art. Ithaca: Cornell University Press, 1991.

Dipert, Randall R. Artifacts, Art Works, and Agency. Philadelphia: Temple University Press, 1993.

Eaton, Marcia. "Art, Artifacts, and Intentions" American Philosophical Quarterly vol. 6 no. 2 (April, 1969): 165-169.

Elder, Crawford L. "Artifacts and Mind-Independence." In Artefact Kinds: Ontology and the HumanMade World, ed. Maarten Franssen et al., 27-43. New York: Springer, 2014.

-. "On the Place of Artifacts in Ontology." In Creations of the Mind, ed. Eric Margolis and Stephen Laurence, 33-51. Oxford: Oxford University Press, 2007.

Evnine, Simon. Making Objects and Events. Oxford: OUP, 2016.

—. "Mass Production.” In The Nature of Ordinary Objects, ed. Cumpa and Brewer, 198-222. Cambridge: CUP, 2019.

—. "Ready-Mades: Ontology and Aesthetics" British Journal of Aesthetics vol. 53 no. 4 (October, 2013): 407-423.

Fine, Kit. "Essence and Modality" Philosophical Perspectives vol. 8 (1994): 1-16.

Franssen, Maarten and Peter Kroes. "Artefact Kinds, Ontological Criteria and Forms of MindDependence." In Artefact Kinds: Ontology and the Human-Made World, ed. Maarten Franssen et al., 63-83. New York: Springer, 2014.

Friedell, David. "Abstract Creationism and Authorial Intention" The Journal of Aesthetics and Art Criticism vol. 74 (2016): 129-137.

-. "Abstract and Concrete Products: A Response to Cray" The Journal of Aesthetics and Art Criticism vol. 75 (2017): 292-296.

Goff, H. Douglas and Richard W. Hartel. Ice Cream, $7^{\text {th }}$ ed. Boston, MA: Springer, 2013.

Goodman, Jeffrey. "On Inadvertently Made Tables: a Brockean Theory of Concrete Artifacts" Acta Analytica (2020): https://doi.org/10.1007/s12136-020-00438-w.

Gould, James L. “Animal Artifacts.” In Creations of the Mind, ed. Eric Margolis and Stephen Laurence, 249-266. Oxford: Oxford University Press, 2007.

Grandy, Richard. “Artifacts: Parts and Principles.” In Creations of the Mind, ed. Eric Margolis and Stephen Laurence, 18-32. Oxford: Oxford University Press, 2007. 
Hilpinen, Risto. “On Artifacts and Works of Art” Theoria vol. 58 (1992): 58-82.

Houkes, Wybo and Pieter Vermaas. "Actions versus Functions: A Plea for an Alternative Metaphysics of Artifacts” The Monist vol. 87 no. 1 (2004): 52-71.

—. "On What Is Made: Instruments, Products, and Natural Kinds of Artefacts." In Artefact Kinds: Ontology and the Human-Made World, ed. Maarten Franssen et al., 167-190. New York: Springer, 2014.

Hughes, Jesse. “An Artifact is to Use: An Introduction to Instrumental Functions” Synthese vol. 168 (2009): 179-199.

Irmak, Nurbay. "The Problem of Creation and Abstract Artifacts" Synthese (2020): https://doi.org/10.1007/s11229-020-02672-6.

Juvshik, Tim. "Function Essentialism about Artifacts" Philosophical Studies, (2021): https://doi.org/10.1007/s11098-020-01594-w.

Kelemen, Deborah. “The Scope of Teleological Thinking in Preschool Children” Cognition vol. 70 (1999): 241-272.

Kelly, Jack. Gunpowder: Alchemy, Bombards, \& Pyrotechnics: The History of the Explosive that Changed the World. New York: Perseus Books, 2004.

Khalidi, Muhammad. “Mind-Dependent Kinds” Journal of Social Ontology vol. 2 no. 2 (2016): 223-246.

Korman, Dan and Chad Carmichael. "What Do the Folk Think about Composition and Does It Matter?” In Experimental Metaphysics, ed. David Rose, 187-206. London: Bloomsbury Academic Press, 2017.

Kornblith, Hilary. "How to Refer to Artifacts." In Creations of the Mind, ed. Eric Margolis and Stephen Laurence, 138-149. Oxford: Oxford University Press, 2007.

—. "Referring to Artifacts" Philosophical Review vol. 89 no. 1 (January, 1980): 109-114.

Koslicki, Kathrin. Form, Matter, Substance. Oxford: OUP, 2018.

—. The Structure of Objects. Oxford: Oxford University Press, 2008.

Levinson, Jerrold. “Artworks as Artifacts.” In Creations of the Mind, ed. Eric Margolis and Stephen Laurence, 74-82. Oxford: Oxford University Press, 2007.

Lewis, David. On the Plurality of Worlds. Malden, Massachusetts: Blackwell Publishing, 1986.

Lopes, Dominic McIver. "Art without 'Art”" British Journal of Aesthetics vol. 47 no. 1 (January, 2007): $1-15$. 
Lowe, E. J. "How Real are Artefacts and Artefact Kinds?" In Artefact Kinds: Ontology and the HumanMade World, ed. Maarten Franssen et al., 17-26. New York: Springer, 2014.

Mackie, J. L. Ethics: Inventing Right and Wrong. Harmondsworth: Penguin Publishing, 1977.

Mag Uidhir, Christy. Art and Art-Attempts. Oxford: OUP, 2013.

Merricks, Trenton. "No Statues” Australasian Journal of Philosophy vol. 78 no. 1 (2000): 47-52.

National Research Council. Black and Smokeless Powders: Technologies for Finding Bombs and the Bomb Makers. Washington D. C.: National Academy Press, 1998.

Olivero, Irene. "Function Is Not Enough" Grazer Philosophische Studien vol. 96 no (2019): 105-129.

Petroski, Henry. The Evolution of Useful Things. New York: Random House, 1992.

Preston, Beth. A Philosophy of Material Culture: Action, Function, and Mind. New York: Routledge, 2013.

—. "Philosophical Theories of Artifact Function." In Philosophy of Technology and Engineering Sciences, ed. Anthonie Meijers, 213-233. Amsterdam: Elsevier, 2009.

Reydon, Thomas A. C. "Metaphysical and Epistemological Approaches to Developing a Theory of Artifact Kinds." In Artefact Kinds: Ontology and the Human-Made World, ed. Maarten Franssen et al., 125-144. New York: Springer, 2014.

Rosen, Gideon. “Objectivity and Modern Idealism: What is the Question?” In Philosophy in Mind, eds. Michaelis Michael and John O'Leary Hawthorne, 277-319. Netherlands: Kluwer Publishers, 1994.

Schaffer, Jonathan and David Rose. "Folk Mereology is Teleological" Nô̂s vol. 51 no. 2 (2017): 238270.

Scheele, Marcel. "Function and Use of Technical Artefacts: Social Conditions of Function Ascription" Studies in History and Philosophy of Science vol. 37 (2006); 23-37.

Soavi, Marzia. “Antirealism and Artifact Kinds” Techné vol. 13 no. 2 (Spring, 2009): 93-107

Thomasson, Amie. "Artifacts and Human Concepts." In Creations of the Mind, ed. Eric Margolis and Stephen Laurence, 52-73. Oxford: Oxford University Press, 2007.

—. "Artifacts in Metaphysics." In Philosophy of Technology and Engineering Sciences, ed. Meijers, 191-212. Amsterdam: Elsevier, 2009.

—. Fiction and Metaphysics. Cambridge: Cambridge University Press, 1999.

—. "Public Artifacts, Intentions, and Norms." In Artefact Kinds: Ontology and the Human-Made World, ed. Maarten Franssen et al., 45-62. New York: Springer, 2014. 
-. "Realism and Human Kinds" Philosophy and Phenomenological Research vol. 67 no. 3 (November, 2003): 580-609.

Thomson, Judith Jarvis. “The Statue and the Clay” Noûs vol. 32 (1998): 149-173.

Van Inwagen, Peter. Material Beings. Ithaca: Cornell University Press, 1990.

Wiggins, David. Sameness and Substance Renewed. Cambridge: Cambridge University Press, 2001.

Xhignesse, Michel. "Failures of Intention and Failed-Art" Canadian Journal of Philosophy vol. 50 no. 7 (2020): 905-917.

Zimmerman, Dean. "The Constitution of Persons by Bodies: A Critique of Lynne Rudder Baker's Theory of Material Constitution” Philosophical Topics vol. 30 (2002): 295-338. 